Of MANNeRs AND HedgeHOgS: BUILDING CLOSENESS by MAINTAINING DISTANCE

Iza Kavedžija

University of Exeter

Sociology, Philosophy and Anthropology

University of Exeter

Amory Building

Rennes Drive

Exeter

EX4 4RJ

United Kingdom

I.Kavedzija@exeter.ac.uk 


\title{
Of ManNeRs ANd Hedgehogs: BuILDING ClOSEnESS by MAINTAINING \\ DISTANCE
}

\begin{abstract}
This paper explores how the Japanese inhabitants of a densely populated urban neighbourhood negotiate proximity and distance in their social relationships. Based on ethnography of a community salon in the city of Osaka, the paper explores how topics and styles of conversation, modes of interaction between salon-goers, are constituted with respect to a pervasive concern for manners and for the emotions of others. Focusing on the importance of "form" and its relevance for morality, I argue that formality serves as an enabling device for creating new relationships among older Japanese, preserving sociality while protecting oneself and others from the burdens of emotion and excessive proximity. By focusing on the ethics of 'doing things properly' (chanto suru) I explore the relationship of manners and care. By taking manners into account, I turn my attention in this article to those relationships crafted and maintained amongst those to whom one is not very close, and with whom one may not wish to become intimate. In this way, I explore the question of how to treat well those towards whom one wishes to maintain distance. Or, in other words, how to care for those who are not one's friends?
\end{abstract}

Morality, care, distance, intimacy, aging 


\section{Of ManNeRs ANd Hedgehogs: BuILDING ClOSEnESS by MAINTAINING}

\section{DISTANCE}

Contemporary urban Japan is increasingly described as a 'society without ties' (muen shakai), and the problem of atomisation is widely discussed in the national media. The number of people living alone, in single households, has increased over the past several decades, among the urban young as well as the elderly. In the downtown area of Osaka, where I conducted around 14 months of fieldworki, a high proportion of the population was comprised of people over the age of 65, and many of them lived on their own ${ }^{i i}$. I met most of them in a community salon, a café-like space established by a local non-profit organization with the aim of combating social isolation and creating new ties in the neighbourhood. Yet while the middle-aged and older residents I knew remembered well the closer, denser neighbourhood ties of times past, they did not idealize them. Many spoke of neighbours dropping by at all times of day, perhaps to borrow something, exchanging greetings on their way to the shops; but they also remembered all too well the burdens imposed by relationships requiring complex obligations of gift exchange, and all-too-widespread knowledge of precisely who was doing what and when. The salon staff also made it clear that they did not want to go back to the community of the 'olden times'. When I asked Nakajima san, one of the salon's founders, about its purpose, her reply was illuminating:

[We are doing this] so that people wouldn't become isolated, live somewhat spaced out, private....[But] You see, while hedgehogs might want to pile up for warmth, they might also feel uncomfortable when they are too close together. Being too close can create annoying relationships (okorisuru yōna kankei), so we want to create a place where people can cordially live together (minna de nakayoku kurashite) while still maintaining a sense of distance (kyōrikan). That is our purpose.

My aim in this article is thus to is explore how elderly Japanese manage this pervasive tension between distance and intimacy in their everyday lives, especially through their careful use of distancing mechanisms such as politeness and an attention to 'form', or 'doing things properly'.

\section{AN ETHICS OF 'DOING THINGS PROPERLY'}

Recent work on morality and ethics in anthropology has sought to move away from the study of proscriptive moral systems, and towards explorations of the lived experience of ethics and of moral judgements in everyday life. According to James Laidlaw, the paucity of theoretical investigation by anthropologists into the ethical realm can be attributed in part to the legacy of Durkheim: if the good is closely associated with the collective, then independent ethical judgement appears both impossible and irrelevant. Studying the broader moral order in the form of rules emerges as central: '...he devoted so much explicit attention to morality, and seems at first sight to have achieved its integration into the study of society, his writings reveal the disabling consequences of identifying the social with the moral...' (Laidlaw 2002: 312). To 
overcome this problem much of the work of the anthropologists interested in ethics and morality has thus moved away from studying abstract moral codes.

Instead, one major strand in the anthropological studies of morality concerns 'ordinary ethics'. In contrast to those theorists of morality who attend to extraordinary situations of life and death and situations of crisis, 'ordinary ethics' suggests that human beings are always subject to ethics, no matter what they are doing. Ethics is part of the ordinary and permeates everyday life in often unacknowledged and implicit ways: "the "ordinary" implies an ethics that is relatively tacit, grounded in agreement rather than rule, in practice rather than knowledge or belief, and happening without calling undue attention to itself' (Lambek 2010:3). In contrast to that perspective focusing on moments of moral breakdown (Zigon 2007), 'ordinary ethics' proponents suggest that moral judgements need not only be seen as a space of reflection created when one is able to 'stand back' from the flow of everyday life, but is indeed submerged in it. As Veena Das put it powerfully:

I will argue for a shift in perspective from thinking of ethics as made up of judgements we arrive at when we stand away from our ordinary practices to that of thinking of the ethical as a dimension of everyday life in which we are not aspiring to escape the ordinary but rather to descend into it as a way of becoming moral subjects. Such a descent into the ordinary does not mean no attempt is made to work on this ordinary in order to improve one's conditions of life but that such work is done not by orienting oneself to transcendental, objectively agreed-upon values but rather through the cultivation of sensibilities within the everyday. One way to put this is in terms of the labor of bringing about an eventual everyday from within the actual everyday (Das 2012: 134; emphasis mine)

In this article I observe the ethical practices of crafting social relations of care among older residents of Shimoichi, a rapidly aging downtown neighbourhood of Osaka. They do this by being attentive and responsive to others, considerate and concerned. They also do it by taking care to 'do things properly' and thus attending to form; by being polite and minding their manners, and in this way doing 'right' by others and being considerate (omoiyari). While embedded in and certainly part of the everyday and mundane, my Osakan friends and acquaintances do not merely take this world for granted, but indeed ask more of it, they rework it and perhaps, elevate it: rather than descending into the ordinary, following my interlocutors thus felt like an ascentiii. It therefore seems to me that while this project shares much with 'ordinary ethics', it also takes a somewhat different perspective, by focusing on manners as part of the practice of care. At first glance, manners and care would appear to fall into two different spheres of activity: manners matter most when one is interacting with those to whom one is not especially close; care in discussions of ethics is typically associated with the intimate sphere, especially the circle of close family members. By taking manners into account, I turn my attention in this article to those relationships crafted and maintained amongst those to whom one is not very close, and may not wish to become intimate with. In this way, I explore 
the question of how to treat well those towards whom one wishes to maintain distance. How can one, in other words, care for those who are not one's friends?

\section{CARE AND MORALITY}

Care is a moral practice, as Arthur Kleinman powerfully argues: 'caregiving is a defining moral practice... that makes caregivers, and at times even care receivers, more present and therefore more fully human' (2009:293). If care is moral, it is undoubtedly also relational: understood broadly (beyond medical settings), caring for others underpins sociality itselfiv.

Feminist work on the ethics of care moves away from an understanding of ethics as a sphere of abstract moral principles and towards a focus on the practice of care, based on a recognition that rather than being predominantly independent actors, humans live lives marked by dependence on others. Care is here seen as one of the defining human activities, and the need of those who depend on us for care is recognized as pressing (Held 2006: 11). As such, 'An ethics of care directs our attention to the need for responsiveness in relationships (paying attention, listening, responding)' (Gilligan 2011). The focus in this article is on care in the latter sense - as a form of attention to others ${ }^{\vee}$ and a practice, but one which need not be restricted to situations of pronounced dependence (as is the case, for instance, between parent and child). I am interested in the relations of care crafted between the inhabitants of Shimoichi, a neighbourhood in the Japanese city of Osaka, who were actively engaged in crafting in a network of support. My interlocutors cultivated a range of dependencies in order to avoid burdening their families or relying solely on state support; they cultivated multiple relationships of dependence in order to maintain a certain degree of independence. While more pronounced in older age, this might be exemplary of social life more generally: recognizing independence as composed of a series of relations of interdependence. While I have explored relations with institutions, local governments and various voluntary care providers elsewhere (Kavedžija forthcoming; Kavedžija 2015), in this article I focus on horizontal ties created and cultivated with care.

A predominant concern in the interactions cultivated by my elderly interlocutors in Shimiochi, a concern that pervades a whole range of daily activities, is that of form, or with the right way of doing things: what they would term chanto suru, or doing things properly. This was a concern even in those activities that people seem to pursue virtually alone, such as preparing a cup of tea or tidying away clothes. How should we reconcile this respect for principle (or set of principles, or guidelines) with an ethics of care which ostensibly rejects the primacy of principles, of abstract rules? In other words how can one find morals in manners? I wish to argue that this happens in two ways. First, morality as 'doing things right' orients the person to others, but also to the environment: to things, processes and work. Second, politeness and attention to form are used to facilitate social interactions. In other words, doing things properly, or in the right way, is seen precisely as a way to express one's concern for another. The distance created by politeness allows for the establishment of desired social ties within a caring community. 


\section{LIVING WITH OTHERS: UNDERSTANDING FREEDOM AND CARE}

My older friends and acquaintances who gathered in the community salon were diverse in many ways - some were in their late sixties and perceived as quite young, by the several octogenarians and a couple of nonagenarians. The majority of the 20-30 or so regulars were women, but several retired men were also to be seen on a regular basis. Some were comfortably off, living in old townhouses and with pensions from husbands in civil service, while a few lived in small apartments further away, or worked to supplement their very low pension. Overall, they identified as middle-class and the differences were not visible or known (I learned some of these things in interviews when we grew closer, after many meetings in the salon). Mostly, one could say they were neither poor nor particularly affluent. The generational differences were considerable, as hardships and the challenges they experienced came at different stages in their lives. The Second World War, shortages, the years of prosperity followed by a period of economic stagnation, therefore affected them differently.

Tanaka san, in her late eighties during my fieldwork, had already been a mother of two when the house she lived in during World War II went up in flames. She walked alone from Osaka, she told me, with two young children in tow, all the way to the rural household of her fatherin-law. The shortages that followed the war were less noticeable there, and the traumatic memories are of the bombings itself, rather than the scarcity. For many years that followed she lived as a housewife, her days marked by the care of her children and husband, who worked as a civil servant. Still frugal and practical, Tanaka san made an obvious effort to know of important services and events that could interest her and her acquaintances in the salon, and willingly shared this knowledge as a way of offering support to others. More than once I heard her make arrangements on behalf of someone else in need of help: asking a younger retired man to ask Oku san if she needed help fixing her window; or suggesting that the young nephew of Sakai san, who was looking for employment, consider the opening in the day-care centre she had just heard of. Always cheerful, Tanaka san made a point of ensuring that all around her felt comfortable - that the heating was not too high, that the chair was ready for them, that they were greeted, and at times pointing out: 'look, everyone Mori san is leaving now'. In this way she was gently and subtly making sure that no-one felt bad: neither the person leaving for being neglected, nor the person engaged in a chat for bring inconsiderate.

Sato san, now in his early seventies, had worked as a manager of a small company for many years, and had felt responsible for his workers. Whenever he came into the salon he would take his time politely to inquire about the health of others, to ask after their news. In this way he expressed concern and, wherever possible, offered help, while at the same time affirming the bond with whomever he was speaking by invoking common acquaintances. Whenever he went away for a short trip with his family, he returned with presents of food, as is the custom. These were always shared carefully, and as they were not intended for anyone in particular, but simply for anyone present, this was a way of making sure that no undue burden was felt by the recipients. 
What is not apparent from these examples is how my older friends felt constrained by their concern with politeness. This was indeed at times an issue for them, and withdrawal to the private sphere, having a walk or going back home for a nap, or simply moving to the corner to read, was often an acceptable solution. If the anthropology of ethics is primarily an anthropology of freedom, in shifting our attention to care as mutual and manners as a kind of a proscriptive ethical system, are we losing sight of free moral agents? For Laidlaw, reflective freedom is seen as the basis and prerequisite for ethical life, even if such an actor then decided to adhere to a set of moral precepts (Laidlaw 2013). Autonomy and freedom were certainly not unimportant for my interlocutors, and I would not wish to imply that they were not reflexive and sensitive moral agents. But their concern with autonomy was very much inflected with care and concern for others. Indeed, I would like to argue that the entwinement of these issues becomes particularly salient in later years, for two reasons: the gradual loss of consociates; and increasing recognition of the importance of care, or of the need for the support of others. Furthermore, for the attitude of care in this context to be fully realized it had to include a respect of the sphere of autonomy of the other. Much attention and thought was given to treading lightly, behaving the right way so as not to encroach on others. In other words, an ethics of care through 'doing things properly', while relational, is also about allowing a space for the freedom of the other.

\section{SINCERITY AND CARE}

Writing about ethics, Lambek reflects on care as not just a specific practice but an attitude or 'at least an attribute of practice, in the manner that we "take care" not only to say and do the right thing but to do things well, to do them carefully' (Lambek 2010:16). This resonates well with the statements and practices of my older friends in the field: I was shown how to greet properly, taught how to dry the cups properly, how to look after the teapots and even dirty rags. They considered the position of chairs for each newly arrived guest, checked the heating settings, inquired about acquaintances tactfully, and took pride and joy in doing things the right way. 'Chanto suru' can thus be seen, I argue, as an act of care.

But does doing things carefully, and thus with a particular disposition, necessarily imply doing them with the right kind of motivation? Is care to be seen as a reflection of some kind of inner attitude, or positive emotional state? In other words, must care be sincere? This issue in fact pervades much work on the ethics of care. Virginia Held, for example, argues that care is both a value and a practice and that good care is not just done adeptly (in the right way) but also with the right kind of motivation (Held 2006: 4). But this motivation, as Felicity Aulino (2102) argues in the case of carers in Thailand, need not be seen simply as an expression of warm or positive emotions. At times, daughters enacted and performed care despite their inner emotional turmoil. This was seen to be more important - they were 'good daughters' because they were doing the right things. She describes the performance of care as akin to a ritual, where the action matters more than the presumed emotional state of the actor (Aulino 2012). 
In fact, we could add, the performance itself affects us, thus fostering a particular emotional state.

While motivation is undoubtedly seen as important in the ethics of care, emphasis is nevertheless placed squarely on the relations of care, that is, on the relational nature of the interaction, not between independent individuals but between actors already bound to others (Held 2006: 12). Two or more people may have virtuous motivations, but this does not straightforwardly translate into a practice of care: they can still have a relationship that is fraught or unhelpful. As Held put it, 'a caring relationship requires mutuality and the cultivation of ways of achieving this' (ibid.: 53).

\section{SITTING TOGETHER: ON SALON SOCIALITY}

While the salon resembled a café, it also differed from it in some ways: not only was it staffed by volunteers, it also only had two large tables in the centre of the room, rather than a number of small tables lined along the walls. It was warmly lit, but did not always seem inviting for a first-time visitor. As of the veteran visitors mentioned once, remembering her first visit:

This place is hard to enter (hairinikui). When I first came here I was reluctant, because you don't exactly know what this place is. It doesn't look like an office or a shop, but it's somewhat different from a café, because you can see from the large window at the entrance that everyone's sitting at one of the two large tables. Also, there's no menu or price list out the front. I didn't know what to expect!

This feeling of the salon being difficult to enter, or of being out of place in the salon is, paradoxically, linked to the feeling of it being a warm, welcoming and cheerful place. The laughter and lively chats coming from the inside can be in equal parts inviting and intimidating. The reason for this is a lack of clear information about how open or closed is the circle of people inside, which might make one feel as an outsider. In literature about Japan the twin concepts of inside (uchi) and outside (soto) is often mentioned as an important principle of classification: one either belongs to the group, or does not. This group may be a family, a company, or a class, and the social world comprises a number of such overlapping circles. A public place such as a café, by contrast, does not usually house a tightly knit group, but rather an assemblage of strangers who do not communicate with each other, except with the particular person they arranged to meet: space is divided between strangers and friends. The salon aims to create a different kind of place, where one can talk to others who may not have been acquaintances, but are not strangers either. Equally, one may come to meet a friend in the salon, but most would be reluctant to display particular closeness and intimacy with one person in particular in a way that isolates them from the overall conversation. Around a shared table, common courtesy demands that the conversation can be shared. Frequent visits and many familiar faces undoubtedly create a sense of belonging, especially when even one's short absence is noted by others. Yet the relationships between salon goers could not be described as close or intimate. 
While some visitors appreciated the salon as a place to quietly enjoy an inexpensive hot drink, and some used it to meet up with a friend (much as in any other café), the majority simply came along on a regular basis to enjoy the company of whomever they should run into there, whether quietly listening to a conversation and nodding occasionally, having a casual chat with one or two others during a lull, or participating in a loud and cheerful exchange within a larger group. Conversations in the salon covered a wide array of topics, prominent among which were local news and information, family, politics, and, especially, food.

Many salon visitors happily discussed their family relationships, and in fact frequently complained about their sons, daughters, or daughters-in-law. These more sensitive topics were most often discussed quietly, in smaller groups, especially when people voiced worries or concerns, or felt compelled to complain about a difficult or unfair situation ${ }^{\text {vi }}$. Such concerns, I noticed, were often voiced in a jocular or comical manner. In her work with older Japanese women, Matsumoto (2011) similarly found that painful self-disclosure was often comical or humorous. My feeling was that the need to share one's worries was typically accompanied by a sense that in order not to make the atmosphere overly grim, and so as not to burden others, one must maintain some humorous distance.

Salon goers usually strove for a pleasant atmosphere and avoided confrontation or visible tension. One might assume that this 'unwritten rule' of cheerfulness and conviviality could be constraining, but on several occasions my interlocutors explained that they would rather leave some problem in peace, or simply avoid those with whom they had a disagreement, than miss the opportunity to have fun (tanoshimi). My older friends often mentioned that the salon was a place where people came to enjoy themselves. They didn't often feel like talking about unpleasant things, or burdening others with problems. Yet it would be mistaken to conclude that the conversations were therefore shallow or insincere.

Local politics and daily news comprised a large part of conversations, which is perhaps unsurprising given that these topics were potentially available to everyone. While such conversations usually took the form of lively discussions interwoven with jokes, opinions expressed were typically restricted to worries about the competence of the Japanese government, or the way a particular statement was formulated, or about the trustworthiness of a particular politician: general themes that everyone tended to have an opinion about. Open views about certain political matters were almost never expressed, and while the conversation was rather loud, it rarely took a form where anyone could disagree much with anything that was said. Yet the conversations appeared heated and genuine, with no veiled sentiments.

The Japanese concepts of tatemae and honne are useful in thinking through this issue. Tatemae denotes the external, rule-bound social persona, and is associated with the way one is expected to behave. Honne, by contrast, is supposed to be an expression of one's 'true' self, denoting one's 'true' feelings or the way one would like to act, with one's own interests in mind (e.g. Doi 1973; 1986; Sugiyama Lebra 1976:136, Sugimoto 2003:28). We might therefore be tempted to conclude that what was expressed in these apparently superficial conversations in 
the salon was simply tatemae, while the 'true' feelings of honne were kept private. Such a conclusion would imply that the views expressed were insincere, or somehow less than fully true: a necessary façade in a public situation, a way of maintaining harmony within the group. Of course, the interplay between these two is never so simple, as children in Japan learn early on (Tobin 1992:23-24). Indeed, a number of other factors complicate this overly simple picture based on a duality between public and private spheres ${ }^{\mathrm{vii}}$. A brief story from the salon may help to illustrate my point.

\section{DOING THINGS PROPERLY: EMOTION AND FORM}

A long and heated conversation arose in the salon one afternoon when Mori san told us about his experience earlier that day, when he set out to buy some new ink for his printer, in order to print some photos. But the shop owner had run out of ink cartridges for that model of printer, and simply informed him in a matter-of-fact kind of way. Mori-san was infuriated, and walked an hour to the next-closest printing shop, swearing to himself never again to return. The conversation in the salon now turned to the source of Mori-san's frustration, and it transpired that he did not expect a different service in terms of actions taken, such as taking an order, but was deeply concerned about the 'form' in which the store owner's inability to help him was conveyed. Instead of just stating plainly that they have no more ink, he could have offered an apology or an explanation. This sentiment - that the way the shopkeeper spoke was inadequate - was soon confirmed and restated by everyone in the group, and numerous examples of similar behaviour were listed. On other occasions too, more closely related to interactions within the salon, the general sentiment was not that something should not have occurred, but rather that a message should be conveyed in a particular way. This focus on a particular way things should be done seemed to be present in many other situations: tea should be served properly; guests at salon events should be greeted properly; and so on. It is a matter, as the Japanese put it, of chanto suru, or 'doing things properly'.

These examples indicate that when people are displeased with the words or actions of others, it generally relates to how those others expressed themselves rather than what exactly was said. In other words, the intention of the speaker was less important than the particular forms used. In the (urban Croatian) society in which I grew up, for instance, a polite or pleasantly worded utterance might easily have been construed as insincere and fake, while one's 'real' feeling carried greater significance. Yet here this was conspicuously absent. Such a discourse of intimacy, familiar to the ethnographer, prioritizes the truthfulness of the content, taken to be the essence, such that the intentions of the speaker may be concealed by the words themselves. In this case, such assumption would be misleading - the polite statements are not merely concealing the authentic thoughts and feelings ${ }^{\text {viii }}$.

Notions of sincerity and authenticity rely on expressions of interiority, with truth originating 'inside' one's self, as it were, as opposed to being already given, handed down by tradition (Keane 2002). An understanding of sincerity as an expression of one's inner self is difficult to square with an understanding of personhood as constituted through social relations and 
actions, rather than defined in terms of an inner essence. The Japanese subject, we might conclude, is not a typical 'modern individual', and Japanese personhood has of course often been described as socio-centric. While such a label undoubtedly captures something of importance, I believe it also fails to explain the sense of struggle and effort that my older interlocutors put into negotiating the fine line between sociality and over-closeness. For them, overly formal interactions can lead to the burdens of elaborate gift-giving and an intricate series of exchanges of favours, something they generally now seek to avoid. Formality and politeness can also be seen as distancing mechanisms, or as denoting the boundaries of ingroup and out-group, excluding some while including others. Again, this was something generally avoided in the salon, where the aim was always to create an inclusive space. At the same time, an attention to form, or to 'doing things properly', allowed people to avoid what they perceived to be the burden of excessively close or intrusive relationships. For older Japanese, I would suggest that formality serves precisely as an enabling device, for creating new relationships (like those in the salon), or maintaining sociality, while protecting oneself and others from the burdens of unwanted emotional ties.

Careful attention to politeness and formality thus allowed people to build relationships where sincere views and emotions could be expressed safely, suitably mediated and framed by appropriate forms ${ }^{i x}$. In a context where people are not seen as impermeable units, as discrete individuals coming together, but rather as constituted through social interactions, the distance created by attending to form is actually seen as vital for preserving the self. This emotional space afforded by the judicious use of politeness made it possible for these elderly Japanese to create a sense of non-alienated urban space, without re-creating the tiresome or 'sticky' community of the past. An attention to form did not entail keeping one another at arm's length; but rather, we might say, at a 'needle's length': that is, at just the right distance, neither too close nor too far, to avoid feeling like piled up hedgehogs.

\section{ACKNOWLEDGEMENTS}

The research for this article was supported with grants from Clarendon Fund, Wadsworth International Fellowship of the Wenner Gren Foundation, Japan Foundation and Japanese Society for Promotion of Science.

\section{REFERENCES}

Al-Mohammad, H. 2013. Ethics: Provocation. Cultural Anthropology website, https://culanth.org/fieldsights/216-ethics-provocation, Accessed on 25/10/2017

Aulino, F., 2012. Senses and sensibilities: the practice of care in everyday life in Northern Thailand (Doctoral dissertation).

Borovoy, A. 2005. The too-good wife: Alcohol, codependency, and the politics of nurturance in postwar Japan (Vol. 6). University of California Press. 
Das, V. 2012. Ordinary Ethics, in (ed.) D. Fassin. A Companion to Moral Anthropology. Malden: John Wiley \& Sons: 133-149.

Drazin, A. 2011. Towards and anthropology of care: Cleanliness and consumption in urban Romanian homes. Slovensky Narodopis 59(5): 499-515.

Garcia, A. 2010. The pastoral clinic: Addiction and dispossession along the Rio Grande. Berkeley: University of California Press.

Gilligan, Carol. 2011. Interview on June 21st, 2011. http://ethicsofcare.org/carol-gilligan/. Accessed on 21/01/2017

Held, V. 2006. The ethics of care: Personal, political, and global. Oxford: Oxford University Press.

Hendry, J. 1995. Wrapping culture: Politeness, presentation, and power in Japan and other societies.

Oxford, Clarendon Press.

Hochschild, A. R. 2000. Global care chains and emotional surplus value. In A. Giddens and W. Hutton. On the edge: Living with global capitalism. London: Jonathan Cape, 130-46.

Kavedžija, Iza (2016). The age of decline? Anxieties about aging in Japan. Ethnos 81 (2): 214-237. (Published online 16/05/2014).

Kavedžija, Iza (2015). Frail, independent, involved? Care and the category of the elderly in Japan. Anthropology and Aging 36(1): 62-81. ISSN 2374-2267.

Kavedžija, Iza (2018). Meaning in life: Tales from aging Japan. Contemporary Ethnography Series. University of Pennsylvania Press, Forthcoming.

Keane, W. 2002. Sincerity, "Modernity," and the Protestants Cultural Anthropology 17(1): 65-92.

Kleinman, A. 2009. Caregiving: the odyssey of becoming more human. The Lancet, 373(9660), 292293.

Laidlaw, J., 2002. For an anthropology of ethics and freedom. Journal of the Royal Anthropological Institute, 8(2), pp.311-332.

Lambek, M. 2010. Ordinary ethics: Anthropology, language, and action. New York: Fordham University Press.

Matsumoto, Y., Ed. 2011. Faces of Aging: The lived experiences of elderly in Japan. Stanford, Stanford University Press.

Sennett, R. 2002 [1977]. The Fall of Public Man. London, Penguin.

Stevenson, L. 2014. Life beside itself: Imagining care in the Canadian Arctic. Berkeley: University of California Press.

Sugimoto, Y. 2003. An introduction to Japanese society. Cambridge, Cambridge University Press.

Thelen, T. 2015. Care as social organization: Creating, maintaining and dissolving significant relations. Anthropological Theory 15(4) 497-515.

Tobin, J., 1992. Japanese preschools and the pedagogy of selfhood. In Nancy Rosenberger, ed. Japanese sense of self, pp.21-39.

Zigon, J. 2007. Moral breakdown and the ethical demand: A theoretical framework for an anthropology of moralities. Anthropological Theory, 7(2), 131-150.

\footnotetext{
i The fieldwork was conducted in 2008-9, with follow-up visits throughout 2013.
} 
ii Much has been written about the issues of aging in Japan by Japanese and foreign scholars regrettably, a review of such literature is beyond the scope of this article. For a detailed discussion of issues of aging in Japan, the construction of the category of the elderly in Japan and the research context see Kavedžija 2015; 2016; 2018.

iii Even when failing in my own manners, I never felt judged as not living 'up' to their expectations. And yet, the figure of descent does not seem to suit this setting. Attention to doing things the right way is, arguably, as much about aesthetics as it is about ethics, and while neither beauty nor ethics need be seen as transcendent and divorced from the mundane, the everyday did not seem lowly either.

iv The practice of care makes and unmakes, creates and undoes, social relationships (Thelen 2015). Yet care is not unambiguous, nor necessarily positive, or emotionally 'warm'. Relations of care are often inflected by power (Drazin 2011), and increasingly by the market context in which they take place (Hochschilld 2000). 'Commodified' relations of care are not necessarily 'uncaring', nor is the care provided by close relatives necessarily 'warm', of course (see also Thelen 2015:3). As provided by family members or otherwise, care does not always promote wellbeing; it takes its toll on the carers, and is not always 'good' for those who are cared for. In a radical example, Garcia writes about families of drug users (2010) and the relations of care which at times facilitate drug use. In fact, his discussion somewhat resembles the situation of wives pulled into co-dependence with alcoholics in Japan (Borovoy 2005).

$\checkmark$ This project in this sense resembles what Hayder Al-Mohammad refers to as an ethics of 'being-with.' In an exchange in Cultural Anthropology Fieldnotes, Al-Mohammad suggests that we 'begin an engagement with ethics, then, not with the self, or techniques or technologies of the self, but the 'hurly-burly' of social life itself? What if we were to say that ethics begins at the 'with' of social being, and not the self or the subject'? (Al-Mohammad 2013). He describes some cases of casual gift giving in Iraq after the invasion as a display of such concern for the other - 'one of the small gestures common amongst my Basran friends was to buy a bag of fruit or sweets and simply to drop them off at someone's house...' (ibid.). In response Clara Han refers to this gesture as a 'light touch' that indicates 'great care' and points to the importance of politeness in ensuring that the gesture is read as a joy of sharing and not as an intrusion, for instance. Her reading of this situation bears much resemblance to the sentiment I describe in this article.

vi Furthermore, they were much more likely to occur among women, and I have only witnessed three occasions when men spoke of their family problems. In all three cases the men were speaking quietly with an older woman whom they knew fairly well.

vii Sennett illustrates this change in the understanding of formality and roles as 'empty' as damaging to a meaningful public sphere, as individual character becomes a key to social relationships, even in the public sphere. For example, in community groups people may feel the compulsion to get to know each other in order to have meaningful relationships, but in the process of getting to know each other they become focused on each other's characters and lose sight of their communal action (ibid.:11). Sennett shows that the idea of sincerity and authenticity based on interiority is peculiar to a particular historical period, bound up with processes associated with modernity. Having analysed the trends toward intimacy in the public sphere and some of its consequences, Sennett argues that a healthy public sphere requires a certain level of formality and role-play as a form of protection that allows communication and thus joint action, making the point that 'boundaries around the self are not isolating, but can actually encourage communication with others' (ibid.:10).

viii Enquiring into how form may be considered more or less revealing of intentions than 'essence' could help shed light on particular epistemologies or local ideologies of knowledge. In her book about gifts in Japan, Joy Hendry (1995) proposes that in the Japanese context wrapping might be at least as important as the content of the gift, if not more. In fact, in case of a prestation, it is impossible to separate the content and the wrapping. Extending this idea to language as a form of wrapping, especially polite language, one could infer that form and content change places in terms of priority. Yet rather than investigating this simply in terms of essence and form, it might be more productive to consider the issue with reference to theories of language ideology and politeness. 
ix If the space permitted, a more detailed discussion of sincerity, Japanese ideas of politeness and distinctions between tatemae and honne; omote and ura would be valuable here. For instance, the idea of politeness expressed in the concept of teinei suggests consideration, care and respect, thus effectively binding manners and morality. 